\title{
The Role of Illness Perceptions on Health-Related Decision-Making-A Focus Group Study of Patients with Long-Term Conditions
}

\author{
Berit Kjærside Nielsen', Kirsten Lomborg1,2 \\ ${ }^{1}$ The Research Programme in Patient Involvement, Department of Clinical Medicine, Aarhus University, Aarhus, Denmark \\ ${ }^{2}$ The Research Programme in Patient Involvement, Department of Public Health, Aarhus University, Aarhus, Denmark \\ Email: beritkn@clin.au.dk
}

How to cite this paper: Nielsen, B. K., \& Lomborg, K. (2017). The Role of Illness Perceptions on Health-Related DecisionMaking-A Focus Group Study of Patients with Long-Term Conditions. Psychology, 8, 1267-1279.

https://doi.org/10.4236/psych.2017.89082

Received: June 17, 2017

Accepted: July 10, 2017

Published: July 13, 2017

Copyright () 2017 by authors and Scientific Research Publishing Inc. This work is licensed under the Creative Commons Attribution International License (CC BY 4.0).

http://creativecommons.org/licenses/by/4.0/

\begin{abstract}
Facing long-term conditions, patients often find themselves in situations where they need to make health-related decisions. The aim of this study was to gain a better understanding of patient preferences for involvement in decision-making as well as the process of decision-making both inside and outside the hospital setting. Seventeen participants with various long-term somatic conditions and different types of treatment regimens participated in this focus group study. Preference for involvement in decision-making was quantitatively measured prior to the interviews using the Control Preference Scale. To obtain the qualitative data, an interpretive description strategy was used. The Self-Regulation Model of illness perceptions was applied as a conceptual framework for discussing the findings. A number of discrepancies between questionnaire- and interview data were discovered, indicating that cognitive beliefs about personal involvement in decision-making are influenced and changed by emotions as well as a number of contextual actors, including personal values concerning everyday quality of life. This study provides insight into understanding how context influences self-regulation of health related decisions amongst patients with a number of long-term conditions. Moreover, decisions are not isolated events, they evolve over time. Thus, data on patients' desired level of involvement in decisions based on questionnaire responses alone should be interpreted with caution. Healthcare providers may benefit from exploring the patients' illness representation in the decision process and thus reduce the risk of talking at cross-purposes.
\end{abstract}

\section{Keywords}

Illness Perceptions, Decision-Making, Long-Term Conditions, Qualitative Research 


\section{Introduction}

When people are diagnosed with a long-term condition, the need to make health-related decisions may become a central part of their everyday life. Nowadays, patients' role in health- and treatment-related decision-making has started to change in the direction of shared decision-making (Blair \& Légaré, 2015). This is due to a number of reasons such as the increase of long-term conditions, unlimited access to information outside of the hospital setting, expectations for patient autonomy in medical decisions, availability of more than one treatment option, and acknowledgement of patient preferences and values (Woolf et al., 2005). Empirical research indicates that patients actively involved in treatment-related matters concerning their illness are more knowledgeable about their condition, more confident in their ability to manage their condition, and more likely to ask questions in the encounter with healthcare providers (Mosen et al., 2007; Nielsen, Mehlsen, Jensen, \& Zachariae, 2013).

A recent systematic review and meta-analysis suggests that what you think about your illness matters in determining your health outcomes (Broadbent et al., 2015). Thus, a patient's perception of their illness is an important factor to consider in the process of making health-related decisions. Today, information about treatment and health plans is more available than ever in an effort to help patients increase control over their health-care experiences and health outcomes. However, experimental research has shown that emotions contribute to healthrelated decisions made in response to numeric medical information (Peters et al., 2009). In addition, research has also shown that people are often ignorant of their actual values and preferences when they evaluate information. Instead, people tend to construct their values and preferences immediately when asked to make a specific decision; thus at the moment of choice, people check in on their emotional state about an option and ask themselves how they feel about it. In this way, emotions guide patients' decision process (Lichtenstein \& Slovic, 2006; Schwarz \& Clore, 2003).

During the course of illness, patients face many decisions both inside- and outside the specific encounter with healthcare providers. Patients are part of the decision-making about medical procedures and treatments, adherence to treatment, as well as decisions regarding self-care (Thorne, Paterson, \& Russell, 2003). According to the Self-Regulation Model of illness perceptions, patients engage in a continuous process of decision-making involving an integrative system of physical, cognitive, and emotional information in an effort to uphold balance (Leventhal, Diefenbach, \& Leventhal, 1992). Patients thus develop representations of illness, upon which they repeatedly consider and evaluate decisions about health and health behavior. Illness representations incorporate cognitive beliefs (e.g., causes, consequences, controllability, identity, timeline) with emotional reactions to the impact of illness on everyday life and they interact through self-regulatory processes (Leventhal, Brissette, \& Leventhal, 2003).

In the present study, we investigated decision-making in a broad sense beyond single-event decisions to include everyday decisions in other aspects of self-care 
that may have a direct or indirect impact on the course of illness or psychological well-being. In the following, we use health-related decision-making as an overall term. As underlying psychological processes are important contributors in the course of decision-making, we applied the Self-Regulation Model of illness perceptions as a conceptual framework for discussion of findings. By doing so, we tried to gain a deeper understanding of the beliefs and emotions guiding patients when making health-related decisions.

\section{Methods}

The research questions in the present study focused on patients' understandings of patient involvement, including factors that may influence decision-making when living with a long-term condition. We used interpretive description to guide our study as this method facilitates the generation of knowledge applicable in healthcare with focus on information that would be important to healthcare providers (Thorne, 2016). We used purposive sampling to ensure a diverse sample, allowing recruitment of patients with different backgrounds, ages, and perspectives on involvement in various areas of treatment and care (Coyne, 1997). Focus groups were preferred over individual interviews because of its ability to make use of group dynamics to stimulate discussion, and to gain insights into the patients' shared understandings (Morgan, 1997).

\subsection{Patients and Setting}

In order to get as many perspectives as possible regarding the decision-making process, and to look for similarities as well as differences across diseases, patients were recruited from three different clinical departments at a large Danish university hospital. We focused on patients with one of four specific somatic conditions: Kidney disease, ulcerative colitis, breast cancer, and malignant melanoma. The department management of each clinical department approved participation. Patients were recruited on-site by trained project nurses using the following inclusion criteria: 1) age 18 years or older, 2) experiencing one of the following conditions: Kidney disease requiring dialysis, ulcerative colitis having undergone pouch surgery, breast cancer in the phase of considering secondary reconstruction, or malignant melanoma in the phase of follow-up, 3) ability to communicate in Danish, and 4) no severe cognitive impairments. In addition, project-nurses were instructed to recruit patients' representative, so far as possible, in terms of gender, age, and socio-economic status. The focus group interviews took place at a meeting room in the clinical departments. Before each interview session, patients were properly introduced and offered a small refreshment. The focus groups were moderated by the first author, while a senior researcher (the second author or her colleague) took notes.

\subsection{Materials}

We developed a focus group interview guide consisting of open-ended questions and discussion prompts based on a review of the research literature on patient 
involvement, including health-related decision-making. During the sessions, it was ensured that all topics listed in the interview guide were covered. The moderator only intervened if necessary by probing questions and following up on topics discussed in the focus group to ensure all the participants would understand. Prior to the focus group sessions, participants filled in a questionnaire to obtain basic demographic information. Moreover, they were asked to complete the Control Preferences Scale measuring the degree of control an individual wish to take in decisions on medical treatment (Degner, Sloan, \& Venkatesh, 1997). The scale is frequently used in research and the preferred decisional roles range from the patient being the primary decision maker (1: active role or 2: patient-led with physician involvement), through shared decision-making (3: collaborative role), to the patient being the passive recipient of the physician's decision (4: physician-led with patient involvement or 5: passive role).

\subsection{Data Analysis}

Data from the Control Preference Scale was analyzed using IBM SPSS Statistics 21. All interviews were recorded digitally and transcribed verbatim by a research assistant, and MS Word was used for management and analysis of the qualitative data. In an attempt to disclose tacit knowledge and thus expand our comprehension of the foundation on which health-related decisions are made, we sought to identify occurrences of decision-making originating in the patients themselves as well as in the interaction with their environment. In line with interpretive description, the first author read the data transcripts repeatedly to become familiar with the data, and also wrote down initial topics as well as other ideas and analytical curiosity that attracted her attention. Secondly, a reading close to the text was performed, identifying key words, sentences, and discussions between participants revolving around the research questions. During this phase, various aspects of health-related decision-making were disclosed. Both authors discussed the findings based on existing research; once findings resonated with the empirical data and the empirical data could be expressed through the analytical process, an agreement was reached on the interpretations made. Finally, we compared the responses from the questionnaire data with our findings from the qualitative data to consider whether the data complemented or contradicted each other. Discrepancy was considered constructive if it would lead to a deeper understanding of the findings (Farmer, Robinson, Elliott, \& Eyles, 2006).

\subsection{Ethics}

The participants gave their written informed consent. According to Danish law, the present study did not need ethical approval.

\section{Results}

The five focus group interviews lasting between 90-120 minutes were held between December 2013 and February 2014. Participating patients were aged between 19 and 73 years $($ mean $=46$ years), and 11 were women (Table 1$)$. In 
Table 1. Patient sample $(\mathrm{n}=17)$.

\begin{tabular}{|c|c|c|c|c|c|c|}
\hline Treatment & & $\begin{array}{l}\text { Inpatient } \\
\text { dialysis }\end{array}$ & $\begin{array}{c}\text { Outpatient } \\
\text { dialysis }\end{array}$ & $\begin{array}{l}\text { Pouch } \\
\text { surgery }\end{array}$ & $\begin{array}{l}\text { Secondary breast } \\
\text { reconstruction }\end{array}$ & $\begin{array}{l}\text { Follow up } \\
\text { after } \\
\text { melanoma }\end{array}$ \\
\hline Sample & & $\mathrm{n}=3$ & $\mathrm{n}=3$ & $\mathrm{n}=3$ & $\mathrm{n}=4$ & $\mathrm{n}=4$ \\
\hline \multirow{2}{*}{ Gender } & Female & $\mathrm{n}=3$ & & $\mathrm{n}=2$ & $\mathrm{n}=4$ & $\mathrm{n}=2$ \\
\hline & Male & & $\mathrm{n}=3$ & $\mathrm{n}=1$ & & $\mathrm{n}=2$ \\
\hline \multirow{2}{*}{ Age } & Mean & 47.7 & 46.3 & 43 & 51 & 42.8 \\
\hline & range & $30-72$ & $22-73$ & $19-58$ & $41-57$ & $30-50$ \\
\hline \multirow{3}{*}{$\begin{array}{c}\text { Educational } \\
\text { level }\end{array}$} & Short & $\mathrm{n}=1$ & $\mathrm{n}=1$ & $\mathrm{n}=1$ & $\mathrm{n}=3$ & $\mathrm{n}=1$ \\
\hline & Medium & $\mathrm{n}=2$ & $\mathrm{n}=1$ & $\mathrm{n}=2$ & $\mathrm{n}=1$ & $\mathrm{n}=3$ \\
\hline & High & & $\mathrm{n}=1$ & & & \\
\hline \multirow[b]{2}{*}{ Marital status } & Living alone & $\mathrm{n}=3$ & $\mathrm{n}=2$ & $\mathrm{n}=2$ & $\mathrm{n}=1$ & \\
\hline & $\begin{array}{l}\text { Living with } \\
\text { partner }\end{array}$ & & $\mathrm{n}=1$ & $\mathrm{n}=1$ & $\mathrm{n}=3$ & $\mathrm{n}=4$ \\
\hline \multirow{3}{*}{ Indication } & Oncology & & & & $\mathrm{n}=4$ & $\mathrm{n}=4$ \\
\hline & Nephrology & $\mathrm{n}=3$ & $\mathrm{n}=3$ & & & \\
\hline & Gastroenterology & & & $\mathrm{n}=4$ & & \\
\hline \multirow{3}{*}{$\begin{array}{c}\text { Control } \\
\text { preference }\end{array}$} & Active & & & $\mathrm{n}=1$ & $\mathrm{n}=1$ & \\
\hline & Collaborative & $\mathrm{n}=2^{*}$ & & $\mathrm{n}=2$ & $\mathrm{n}=1$ & $\mathrm{n}=2$ \\
\hline & Passive & & $\mathrm{n}=3$ & & $\mathrm{n}=2$ & $\mathrm{n}=2$ \\
\hline
\end{tabular}

${ }^{\star}$ One participant did not answer the Control Preference Scale.

three out of the five focus groups, one participant cancelled on the day of the scheduled session due to health issues, leaving only three participants in each of the three groups. In total, 17 patients participated in the focus group interviews.

\subsection{Questionnaire Data}

\section{Decisional Control Preferences}

An equal number of patients indicated a preference for either a collaborative role $(\mathrm{n}=7)$ or a passive role with collaboration (physician-led with patient involvement, $n=7$ ) in decision-making. A Fisher's exact test (data not shown) revealed that decisional control preference significantly differed by gender $(p=0.035)$ with more men preferring a passive role with collaboration. Only one patient indicated a preference for a completely active role, and one preferred an active role with collaboration (patient-led with physician involvement). None of the patients preferred a passive role with no collaboration in decision-making. One patient did not fill in the Control Preference Scale (Table 1).

\subsection{Focus Group Data}

For all participants across the focus groups health-related decision-making reflected a complex system of beliefs and emotions about engaging in what made sense to the patient, given his or her capability to influence a specific situation or outcome.

\subsubsection{Fitting the Various Aspects of One's Illness into Everyday Life}

Health-related decisions made by the patients could be regarded as having a short or long-term goal, and the appraisal of a decision was often based on quality of life in the present moment or in the long run (preventing disease progres- 
sion over time). Decisions with a short-term time perspective could be choosing to eat or drink something that is not healthy when having a certain disease. Patients were often very well aware of their own decision to go against what would be medically advised, but with a lot of self-negotiating between advantages and disadvantages. Compared to the other participants, patients with kidney failure seemed to struggle more with everyday dilemmas related to decision-making on short-term quality of life rather than long-term health.

It's so hard the thing about not being allowed to eat this and that because I don't, you know, have a bad immune system but I know it's also to prevent that it doesn't happen [get a bad immune system] and all, but I can't help it and I can't just give up all the things I used to eat. I simply can't. (Female, 30 yrs., collaborative role).

The young woman's honest statement resonated among the other two participants in the group, and it did not take them long to express solidarity.

You sin too? (Female, 72 yrs., control preference missing)

I do (Female, 30 yrs., collaborative role)

I do, too (Female, 41 yrs., collaborative role)

And I know I do (Female, 30 yrs., collaborative role)

We all do [sin] (Female, 72 yrs., control preference missing)

And I know very well and... (Female, 30 yrs., collaborative role)

But we all do (Female, 72 yrs., control preference missing)

And I really think about it and then I think ah well, probably no harm that I take one more (Female, 30 yrs., collaborative role)

But I understand (Female, 41 yrs., collaborative role).

Considerations, that required the patient to take a long-term perspective on the consequences of a decision, were seen in relation to making a choice on how and where to treat.

I had actually decided before but of course I listened to all they had to say because p-dialysis is by far the best choice in my situation. You know, I'm a student and it's great I don't have to be physically at the hospital three times a week. I would have to, and even though I have to do it at home to, p-dialysis is definitely the best for me so the choice was not hard (Male, 22 yrs., passive role with collaboration).

\subsubsection{Facing Various Types of Decisions-When the "Right" Decision Is Not Obvious}

On the subject of decision-making, it soon became clear that decisions cannot be boiled down to isolated single events during the course of long-term illness. Major decisions are based on the individual patient's ongoing thoughts and concerns, which again are influenced by the patient's health beliefs. Patients in the focus groups did not reflect openly on their decision preferences concerning health-related decision-making in everyday life. However, they were often in situations where they were made aware of the consequences of their illness, 
which triggered considerations about decision-making.

You have to adjust it [prosthesis] every time you do something, when laying on the floor doing pilates or something then it slides you know; this just reminds me about it all the time. It has not just become at natural part of me. And when I'm not wearing it then I think a lot about that people look at me there instead of looking me in the eyes and I also think that's stressful (Woman, 41 yrs., passive role with collaboration).

In situations where a decision could seem obvious from a medical point of view and in connection with specific symptoms and clinical findings, discussions in the focus groups indicated that these signs could lose their impact in the competition with possible competing illness perceptions of the patient.

Then the hospital says that now there are no more medical options, now they recommend surgery and I was not at all ready at that point. So I thought I'll try something alternative [...] And then I lost weight, so if I had not lost weight before I did then; and I thought myself it was the paleo diet that had made me skinny but I have to acknowledge as the doctors said that it probably had something to do with the disease [...] and when I looked bad I was operated, not acutely, but I was operated very fast, so... (Male, 58 yrs., collaborative role).

\subsubsection{Balancing Emotions in Decision-Making}

For many of the patients across the five focus groups, worries and uncertainty related to making a health-related decision were recurrent emotions. When they elaborated on their emotions, it was evident that these were present both on a short- and long-term basis. Emotions were immediately experienced while considering and deciding, but they were also tied to future life circumstances following a decision.

I'm concerned that if it just doesn't get better, if I can still do my job and if I can't, what are my options and so on [...] Where do I go with my worries and I know you can't get a fixed schedule for this but you can hope and see but the mental feeling of insecurity connected to this for months on (Female, 52 yrs., collaborative role).

Emotions also serve as a way to shield oneself from a possible future decision. Negative emotions such as anger could in fact cover up underlying feelings of anxiety and worries associated with having to make a treatment-related decision.

[...] and my mom she kept asking about the dialysis thing, when you are going into dialysis and all, and I got mad with her because I said that, well, I don't want to discuss this because I haven't come that far yet, I don't want to discuss it at all, I don't want to talk about it now. It comes when I'm having dialysis [...] but still, well, I didn't tell them right [the health professionals], I just told my mother (Female, 30 yrs., collaborative role).

Sometimes emotions could confuse and frighten the patient to such an extent 
that there would be doubts about the right treatment. The women, who had a breast removed because of cancer, were all offered adjuvant therapy, and in the process of deciding as well as after the decision had been made, strong emotions could lead to decisional conflict.

But then I start thinking about how does it help because when you lose your hair, lose your eye brows and you lose it all and you stand there looking at yourself in the mirror. You also miss a breast, you are so naked and you are so vulnerable eh, and then you think to yourself, honestly, is it worth it (Female, 49 yrs., collaborative role).

\subsubsection{The Role of Healthcare Providers}

Generally, patients showed a clear interest in being involved in health-related decision-making if they received adequate information. Receiving adequate information also included the doctor's ability to tailor the information to match the patient and to feel that personal values and preferences were actually being taken into account.

And he was very personal about it [the doctor] and said something about that he was older than me, when he was very young, if there was anybody who had offered him a ostomy then he would absolutely go on with a pouch, he had no doubts about that, but now when he was at this age and had the experience, if he was offered it today he would settle for the ostomy. So he had already gotten me started thinking, you know (Male, 58 yrs., collaborative role).

Managing illness on a daily basis would require the patients to make, sometimes difficult, decisions about choosing to live with a number of restrictions to prevent progression of symptoms. More women than men emphasized the need to receive guidance and emotional support from health providers concerning this. If those needs were not met, it could lead to patients almost giving up.

The last time she said [the dietician] why do you come here? because you know what to do and what not to do. So I say yes, I know but I just want to talk to someone. I know, but I just can't, really I can't [follow her diet] (Female, 30 yrs., collaborative role).

\subsection{Synthesis of Data}

When we compared responses from the questionnaire with qualitative statements from the participants, several instances of dissonance occurred. It became clear that more patients expressed a more passive role in the interviews than the preferred role they had indicated in the Control Preference Scale. In the focus group consisting of women who were in the process of considering secondary breast reconstruction, this decision was associated with major ambivalence. So far, for most of the women, there had been no doubt about their breast cancer treatment, and there was a general agreement that there is a significant difference between having to make a decision regarding "necessary" treatment (cura- 
tive treatment) and additional treatment, which initially was perceived by the women as a cosmetic intervention.

Well, it's here [department of plastic surgery] where it's been really difficult because you had to decide what should be done. Sometimes I said to the doctor oh can't you just say what should be done to get the best result, so I don't need to take any responsibility at all myself. Eh then I thought it was difficult eh, and I still find it difficult if what I have chosen is the right thing (Woman, 49 yrs., collaborative role).

However, there were also examples of agreement between the questionnaire responses and interview statements. A woman who was treated surgically for breast cancer was presented with the possibility of adjuvant therapy. She thought that doctors saw her as a demanding patient, when she questioned their manual-like clinical guidelines for treating her breast cancer.

I didn't fit in. No, I didn't just say yes. I said, well I don't know if I want to and I want to know more if it makes a different at all and it's a microscopic difference it makes compared to how uncomfortable it is. And then I still would say that if it wasn't for my family pushing me, then I wouldn't have done it (Female, 57 yrs., active with collaboration).

\section{Discussion}

In the present study we investigated strategies used by patients with long-term conditions when making health-related decisions. In our analysis, it became clear that the very notion of decision preference is challenging. Patients view their circumstances differently and our study indicates that there are many significant and interrelated issues concerning health-related decisions. We found that patients' cognitive beliefs about their preferred level of involvement are shaped by a number of contextual actors, such as the type of decision to be made, trust in your healthcare provider, and personal values concerning everyday quality of life. During the process of interpreting data, we applied the SelfRegulation Model of illness perception with the aim of raising our findings above the specific setting that guided our research question. By considering the continuous cognitive and emotional appraisals made by the patient in healthrelated decision-making, healthcare providers may benefit from exploring the patients' illness representation in the decision process and thus reduce the risk of talking cross-purposes. Doctors can provide accurate diagnoses and offer excellent treatments, but if the treatment does not match the patients' view of illness, they are more likely to seek other means (Petrie \& Weinman, 2012). Attending to the patient's emotions requires flexibility and empathy, rather than standardized questions about values. Moreover, studies in decision-making indicate that emotions not only reflect but also influence patient values (Lichtenstein \& Slovic, 2006). Therefore, healthcare providers need to disclose patients' emotional appraisals regularly to clarify the underlying values. It is problematic to assume that peoples' life values can be easily categorized and defined in advance. Ex- 
amining the various and interrelated actors present in the process of decision-making is thus an important knowledge gap that future research should consider.

Throughout the decision-making process, patients' continuously have to check in on their emotions to make sure that they are guided instead of misled by their emotions. Earlier, the assumption among researchers in decision-making was that when people made a decision that was inconsistent with the evidence presented to them, it had to be due to cognitive limitations (Leventhal et al., 2003). However, as described in the Self-Regulation Model of illness perceptions, thinking and feeling do not always guide people in the same direction. Recent research has shown that subtle contextual factors may trigger strong emotions, such as fear, which may evoke an avoidance reaction (Ubel, 2010). These findings may also explain the discrepancy between our participants' preferred level of involvement in decision-making measured by the Control Preference Scale and their statements in the subsequent focus group interview. In several of the patients it turned out that there was discrepancy between their cognitive appraisal with regard to being involved in decision-making on the one hand and their preferred level of involvement in the present moment, when a decision was made. These findings are in line with a recent study by Massey et al. (2015), who investigated the extent to which goal cognitions, illness perceptions, and treatment beliefs were related to changes in self-reported medication adherence after transplantation. The authors found a discrepancy between beliefs about adherence and actual behavior (Massey et al., 2015). When analyzing the questionnaire data isolated from the qualitative data, we found that statistically more men than women had a preference for the doctor to make the final decisions about treatment while listening to the patient's concerns (passive role with collaboration). This is consistent with previous research, suggesting that men are less likely to desire participation or to seek a second opinion (Henrikson, Davison, \& Berry, 2011). Returning to the complete data, we noticed that the inconsistency between questionnaire response and interview statements was more prevalent among the female participants, indicating that women are more likely to be guided by emotions than men when making a decision. On the other hand, one of the focus groups consisted of women who were in the process of considering secondary reconstruction after breast cancer, and for all these women, there was a lot of uncertainty related to this decision. Uncertainty can also be perceived as decisional conflict, and is defined as an intrapersonal psychological construct experienced when facing decisions that involve risk, loss, regret or challenges concerning life values (Thompson-Leduc, Turcotte, Labrecque, \& Legare, 2016). When the women discussed their curative treatment for breast cancer, the experience of uncertainty was considerably less, suggesting that the type of decision might also explain the gender differences found in our study.

If for a moment, we were to ignore the Self-Regulation Model of illness perception as a potential explanation of the inconsistency between questionnaire responses and interview statements, we could instead question, whether health- 
related initiatives perceived by researchers and healthcare providers to be suitable for patient involvement, is not considered as such from the patient's perspective. We found several examples in our interview data that point in this direction. In particular, our focus group participants did often not fully appraise matters of treatment as an area of patient involvement. Our findings may therefore help expand the understanding of patient involvement in decision-making perceived by the patient. The preference for a collaborative role by the majority of the participants in our study suggests that patients indeed have a need to understand their illness and the choices available to them. It may also suggest a need to be involved to some degree in certain aspects of decision-making, such as decisions affecting everyday quality of life. Nonetheless, it is not guaranteed that every patient want nor understand involvement in decision-making as to take charge along with the doctor when it comes to choosing one treatment over another. The empirical evidence shows that patients are in fact willing to leave much of the responsibility for decisions that require specific expertise to the healthcare provider (Deber, Kraetschmer, Urowitz, \& Sharpe, 2007). The need to consider patients' decisional role preferences appears to be an intrinsic good that cannot be legitimately opposed in the professional care discourse (Boivin, Green, van der Meulen, Legare, \& Nolte, 2009). Our findings may disclose a way to approach patient preferences moving beyond pre-existing assumptions. We must be careful how we interpret patients' desired level of involvement in decisions based on questionnaire responses, and future research must pursue this further to make sure, that clinical changes are made based on the best possible knowledge.

The present study has several limitations. First, as the foundation of qualitative research is to gain in-depth insight into a phenomenon perceived by individuals, the generalizability of the findings in our study is challenging. Only 17 patients participated in the present study, but according to Thorne, patients theoretically represent infinite variation in relation to their experiences with health care, and thus data saturation was not a desired outcome (Thorne, 2016). Another way to determine whether the sample size is sufficient is to apply the concept of information power, proposed by Malterud and colleagues (2015). In their article, they argue that the larger information power the sample holds, the lower $\mathrm{N}$ is needed, and this is determined by items such as study aim, sample specificity, use of established theory, quality of dialogue, and analysis strategy (Malterud, Siersma, \& Guassora, 2015). By critically evaluating these items with regard to the methodology applied in our study, we believe that we were able to get sufficient variation of results despite the low number of patients participating. Secondly, we collected information about the participants' preferred role in decision-making retrospectively, which may have given rise to recall bias. Although patients were asked to discuss their need to be more or less involved, and to describe specific situations that required a decision to be made, we did not observe these situations. Finally, we asked the participants to complete the Control Preference Scale prior to the focus group interview with the aim of investi- 
gating discrepancies between questionnaire- and interview data. What could have strengthened our study was to subsequently introduce the participants to our findings. This could have contributed to a greater understanding of how to interpret the apparent discrepancy.

\section{Conclusion}

This study provides insight into understanding how context influences self-regulation of health related decisions amongst patients with a number of longterm conditions. The results showed that patients' perceptions of themselves and their preferences were often different whether they were reported in questionnaires or in focus group interviews. The study indicates that patients express more eagerness to take part in decisions when considerations about decisionmaking are isolated from the contextual conditions related to real-life.

\section{Acknowledgements}

The authors thank the patients who participated in this study and the nurses at Aarhus University Hospital who assisted with the recruitment of patients. Thank you to Associate Professor Kirsten Bedholm for being a valuable focus group observer and Marianne Godt Hansen for help with proof reading. The study was financially supported by a non-partisan fund: The Novo Nordic Foundation (grant No. NNF12OC0001772).

\section{References}

Blair, L., \& Légaré, F. (2015). Is Shared Decision Making a Utopian Dream or an Achievable Goal? The Patient-Patient-Centered Outcomes Research, 8, 471-476.

Boivin, A., Green, J., van der Meulen, J., Legare, F., \& Nolte, E. (2009). Why Consider Patients' Preferences? A Discourse Analysis of Clinical Practice Guideline Developers. Medical Care, 47, 908-915. https://doi.org/10.1097/MLR.0b013e3181a81158

Broadbent, E., Wilkes, C., Koschwanez, H., Weinman, J., Norton, S., \& Petrie, K. J. (2015). A Systematic Review and Meta-Analysis of the Brief Illness Perception Questionnaire. Psychology \& Health, 30, 1361-1385. https://doi.org/10.1080/08870446.2015.1070851

Coyne, I. T. (1997). Sampling in Qualitative Research. Purposeful and Theoretical Sampling; Merging or Clear Boundaries? Journal of Advanced Nursing, 26, 623-630. https://doi.org/10.1046/j.1365-2648.1997.t01-25-00999.x

Deber, R. B., Kraetschmer, N., Urowitz, S., \& Sharpe, N. (2007). Do People Want to Be Autonomous Patients? Preferred Roles in Treatment Decision-Making in Several Patient Populations. Health Expectations: An International Journal of Public Participation in Health Care and Health Policy, 10, 248-258. https://doi.org/10.1111/j.1369-7625.2007.00441.x

Degner, L. F., Sloan, J. A., \& Venkatesh, P. (1997). The Control Preferences Scale. The Canadian Journal of Nursing Research = Revue Canadienne De Recherche En Sciences Infirmieres, 29, 21-43.

Farmer, T., Robinson, K., Elliott, S. J., \& Eyles, J. (2006). Developing and Implementing a Triangulation Protocol for Qualitative Health Research. Qualitative Health Research, 16, 377-394. https://doi.org/10.1177/1049732305285708 
Henrikson, N. B., Davison, B. J., \& Berry, D. L. (2011). Measuring Decisional Control Preferences in Men Newly Diagnosed with Prostate Cancer. Journal of Psychosocial Oncology, 29, 606-618. https://doi.org/10.1080/07347332.2011.615383

Leventhal, H., Brissette, I., \& Leventhal, E. A. (2003). The Common-Sense Model of Regulation of Health and Illness. In L. D. Cameron, \& H. Leventhal (Eds.), The Self-Regulation of Health and Illness Behaviour (pp. 42-65). London: Routledge.

Leventhal, H., Diefenbach, M., \& Leventhal, E. A. (1992). Illness Cognition: Using Common Sense to Understand Treatment Adherence and Affect Cognition Interactions. Cognitive Therapy and Research, 16, 143. https://doi.org/10.1007/bf01173486

Lichtenstein, S., \& Slovic, P. (2006). The Construction of Preference. Cambridge: Cambridge University Press.

Malterud, K., Siersma, V. D., \& Guassora, A. D. (2015). Sample Size in Qualitative Interview Studies: Guided by Information Power. Qualitative Health Research, 26, 1753 1760. https://doi.org/10.1177/1049732315617444

Massey, E. K., Tielen, M., Laging, M., Timman, R., Beck, D. K., Khemai, R. et al. (2015). Discrepancies between Beliefs and Behavior: A Prospective Study into Immunosuppressive Medication Adherence after Kidney Transplantation. Transplantation, 99, 375380.

Morgan, D. L. (1997). Focus Groups as Qualitative Research. Thousand Oaks, CA: Sage. https://doi.org/10.4135/9781412984287

Mosen, D. M., Schmittdiel, J., Hibbard, J., Sobel, D., Remmers, C., \& Bellows, J. (2007). Is Patient Activation Associated with Outcomes of Care for Adults with Chronic Conditions? The Journal of Ambulatory Care Management, 30, 21-29.

Nielsen, B. K., Mehlsen, M., Jensen, A. B., \& Zachariae, R. (2013). Cancer-Related SelfEfficacy Following a Consultation with an Oncologist. Psycho-Oncology, 22, 20952101. https://doi.org/10.1002/pon.3261

Peters, E., Dieckmann, N. F., Vastfjall, D., Mertz, C. K., Slovic, P., \& Hibbard, J. H. (2009). Bringing Meaning to Numbers: The Impact of Evaluative Categories on Decisions. Journal of Experimental Psychology: Applied, 15, 213-227. https://doi.org/10.1037/a0016978

Petrie, K. J., \& Weinman, J. (2012). Patients' Perceptions of Their Illness. Current Directions in Psychological Science, 21, 60-65. https://doi.org/10.1177/0963721411429456

Schwarz, N., \& Clore, G. L. (2003). Mood as Information: 20 Years Later. Psychological Inquiry, 14, 296-303. https://doi.org/10.1080/1047840X.2003.9682896

Thompson-Leduc, P., Turcotte, S., Labrecque, M., \& Legare, F. (2016). Prevalence of Clinically Significant Decisional Conflict: An Analysis of Five Studies on DecisionMaking in Primary Care. BMJ Open, 6, e011490. https://doi.org/10.1136/bmjopen-2016-011490

Thorne, S. E. (2016). Interpretive Description: Qualitative Research for Applied Practice (2nd ed.). New York: Routledge.

Thorne, S., Paterson, B., \& Russell, C. (2003). The Structure of Everyday Self-Care Decision Making in Chronic Illness. Qualitative Health Research, 13, 1337-1352. https://doi.org/10.1177/1049732303258039

Ubel, P. A. (2010). Beyond Costs and Benefits: Understanding How Patients Make Health Care Decisions. The Oncologist, 15, 5-10. https://doi.org/10.1634/theoncologist.2010-S1-5

Woolf, S. H., Chan, E. C., Harris, R., Sheridan, S. L., Braddock 3rd, C. H., Kaplan, R. M. et al. (2005). Promoting Informed Choice: Transforming Health Care to Dispense Knowledge for Decision Making. Annals of Internal Medicine, 143, 293-300.

https://doi.org/10.7326/0003-4819-143-4-200508160-00010 
Submit or recommend next manuscript to SCIRP and we will provide best service for you:

Accepting pre-submission inquiries through Email, Facebook, LinkedIn, Twitter, etc. A wide selection of journals (inclusive of 9 subjects, more than 200 journals)

Providing 24-hour high-quality service

User-friendly online submission system

Fair and swift peer-review system

Efficient typesetting and proofreading procedure

Display of the result of downloads and visits, as well as the number of cited articles Maximum dissemination of your research work

Submit your manuscript at: http://papersubmission.scirp.org/

Or contact psych@scirp.org 